\title{
APUNTES SOBRE EL REALISMO EN LAS NARRACIONES VISUALES ACTUALES. EL EJEMPLO DE LA ADAPTACIÓN CINEMATOGRÁFICA DEL CÓMIC MARÍA Y YO DE MIGUEL GALLARDO POR FÉLIX FERNÁNDEZ DE CASTRO
}

\author{
ISABELLE TOUTON \\ Université Bordeaux Montaigne
}

\begin{abstract}
A Juan le gustan las formas, la expresión del código. Le gusta que pensamientos y acciones se ajusten como el guante y la mano. Y, eso, ella intentaba demostrarle que no resulta siempre fácil. Ni siquiera posible. Las relaciones entre personas son, al fin y al cabo, formas, frutos de acuerdo, decía él. Y, ella: Eso es mentira. Parece mentira que seas un defensor de la literatura realista y que te interese tan poco el contenido, el fondo de las cosas. Él: Precisamente por eso lo digo, porque soy un defensor del realismo, porque sé que el realismo no es más que una forma de entender lo literario.
\end{abstract}

Rafael Chirbes, Crematorio, 2007

En la novela Crematorio, Rafael Chirbes problematiza, a través de Juan, profesor de literatura adepto del realismo, no solo la relación de la literatura realista con el mundo, sino también la de las teorías políticas, sociales, culturales que desarrollan unos y otros personajes, con la realidad. Consecuentemente, interroga el vínculo entre las formas que toman discursos y textos contemporáneos, y su capacidad para influir en la sociedad desde la que se emiten. El realismo, afirma Juan, "no es más que una forma de entender lo literario", pero aplica esta concepción estética a las relaciones sociales.

Tradicionalmente, en la literatura, la cuestión del realismo pertenece al campo de la ficción, se relaciona con el grado de referencialidad de esta y su capacidad para dar cuenta con "verosimilitud", y de manera más o menos directa, de la realidad. Se suele considerar que la obra ficticia, en particular la novela, se puede alejar del realismo por tres caminos preferentes: el de la alegorizaciónmetaforización de la misma a nivel de la macroestructura de la novela, el uso de técnicas experimentales o vanguardistas que rompan la ilusión novelesca y sobre todo disloquen el flujo cronológico, vivido como natural, de la narración, o bien por el recurso a la imaginación y la creación de mundos maravillosos o 
sociedades de ciencia ficción (este último caso corresponde a menudo a cierta metaforización del mundo histórico). Prácticamente, cuando se adscribe una obra al realismo como movimiento literario, lo que se suele significar es, por una parte, que extrae del mundo histórico temas y personajes que no se benefician comúnmente del papel de protagonistas en los relatos favorecidos por los poderes (clases sociales alienadas, clases dominantes cuyas miserias y perversiones se desvelan, temas tabúes como la muerte, la enfermedad, la pobreza, el mercado del trabajo, la inmigración...), para dar sentido a la realidad desde ciertas ideologías, y gracias a la atención al detalle, a lo cotidiano y a la corporeidad. Por otra parte, se considera que la novela realista es la que se adhiere a unas convenciones institucionalmente leídas como las más aptas para dar cuenta de manera inmediata de lo extraliterario. Como dijo Philippe Hamon, el discurso realista es "como una variedad de discurso manipulador, persuasivo, como un discurso del hacer creer" (1989: 31) 1 .

Un uso actual tiende habitualmente a no discriminar entre "novela realista" y "novela social"2, sirviendo este marbete de eje móvil a partir del cual se establecen dicotomías y jerarquías en el campo de la narrativa española desde los años 80 , una asimilación que se da también en el mundo del cómic: se habla de cómic realista y social, o, según la taxonomía aplicada a las novelas de los años 50 , de realismo social ${ }^{3}$. Lo que nos va a interesar para este estudio, en un primer momento, es de qué manera esta cuestión del realismo -importada de la literatura y de la pintura- se plantea hoy día en las narraciones en imágenes. Empezaremos, pues, con un pequeño balance sobre lo que implica hablar de realismo en este principio de siglo xxı en el terreno de la narración secuencial y de la narración audiovisual. En una segunda parte, a partir del análisis de la adaptación cinematográfica del cómic María y yo de Miguel Gallardo nos proponemos ilustrar en qué medida el acercamiento reciente entre cómic y cine así como el desarrollo de las nuevas tecnologías digitales juegan un papel en la redefinición de las relaciones entre realidad y narración, entre ficción y no ficción, entre imaginación y realismo: "Antes el dibujante de cómic decía: yo tengo más poder que el fotógrafo y el cineasta, pues, con tinta china, creo una civilización en el corazón de África, con unos habitantes de tres metros. El universo digital ha hecho posible lo que antes hacía el dibujante de cómic" (Gubern en Valencia 2014) $)^{4}$.

\footnotetext{
${ }^{1}$ Todas las traducciones del francés son mías.

${ }^{2}$ Se establece por ejemplo la ecuación en Crematorio: "Tu marido, tan interesado por la literatura realista, por la novela social, tiene ahí un buen tema" (Chirbes 2007: 30).

${ }^{3}$ Valgan como ejemplos dos páginas sacadas de Internet: <http://www.savoirsplus.fr/n/la-bdrealiste-et-sociale/n:124> y <http://www.eldiariomontanes.es/20080728/cultura/comic/realismosocial-testimonio-20080728.html> (última consulta 01.12.2013).

${ }^{4}$ Agradezco a Roberto Valencia el haberme proporcionado el texto de este libro de entrevistas de próxima publicación. Este artículo es también deudor de los comentarios y sugerencias de Jesús Alonso, Amélie Florenchie, Guillem Martínez, Germán Labrador Méndez, Lise Segas y Frédéric Sounac.
} 


\section{REALISMO Y NARRACIONES EN IMÁGENES A PRINCIPIOS DEL SIGLO XXI}

\subsection{LA NOVELA GRÁFICA Y LA REALIDAD}

Generalmente, las teorías del cómic son deudoras tanto de las teorías de la literatura como de las teorías del cine (y ambas de la semiótica). Sin embargo, la peculiar historia del cómic europeo y americano ha hecho que la cuestión del realismo y de la ficción se plantee de manera distinta. Se habla ante todo de realismo del estilo gráfico -plástico- concebido como un código inalcanzable porque la exhaustividad, en particular en la restitución de los detalles, es imposible. Así, Thierry Groensteen insiste, junto con otros teóricos, en la distancia que la naturaleza misma del medio establece con la realidad: "La imagen dibujada no comparte con la fotografía o la cinematografía este realismo que André Bazin calificaba de ontológico, esta relación de objetividad con respecto a lo real. No es una 'cámara de registro'. El realismo del dibujo es pues una manera de codificar lo real entre otras" (Groensteen 2012: s/p).

A nivel pragmático, la consecuencia es que las imágenes del cómic nunca van a sumir al lector en una ilusión perceptiva ni en la de estar presenciando una escena que estaría desarrollándose bajo sus ojos, como lo hace una película:

Varios factores se oponen a ello. En particular: la discontinuidad visible del discurso secuencial; el hecho de que el lector no puede olvidar la situación concreta, física, en la que se encuentra, de tener un libro entre sus manos [...] y de darles la vuelta a las páginas, según un ritmo que no se le impone sino del que decide por sí mismo; en fin, el hecho de que cada nueva imagen no oblitera la anterior, no ocupa su lugar, sino que se añade a la precedente bajo la forma de la acumulación, de la colección, permaneciendo la totalidad de las imágenes fácilmente asequibles en cualquier momento. (Groensteen 2011: 89)

Asimismo, Jan Baetens (2001) hace hincapié en cierto grado de no transparencia, de opacidad inherente al dibujo 5 .

Por otra parte, este posible realismo (codificado) del estilo gráfico no es necesariamente el que se elige para las narraciones consideradas como más realistas, es decir, según un uso clásico las que no se adscriben a géneros humorísticos, fantásticos o fantasmagóricos, así como, según un uso más reciente, las narraciones documentales, sociales e íntimas (Groensteen 2012). En no pocos casos, para estas últimas obras, los dibujantes echan mano de un estilo simplificado o caricaturesco, señaladamente en la realización de los personajes, por lo que parecen compartir la idea de Scott McCloud según la cual el lector es más capaz de proyectarse en caras que tienden hacia el ícono que en caras dibujadas de manera realista (1999: 36).

Esta no-definición del cómic realista, en oposición a tipos canónicos de narraciones secuenciales (humorística y fantástica), coincide consecuentemente

\footnotetext{
5 "[The comic] resists [...] figurative transparency; it creates on the contrary a kind of persisting opacity and prevents the act of monstration from being fully transparent and transitive" (Baetens 2001: 149).
} 
con un amplio espectro de géneros de ficción y no ficción. Esto se explica por la propia historia del medio que fue durante un siglo, en su gran mayoría, el espacio de la ficción menos referencial, por lo que permite el dibujo (libertad técnica, no sometimiento a las leyes de la física, en particular de la gravedad y de las proporciones). Estuvo dedicado a la creación de mundos de ciencia ficción o personajes superdotados, o a la deformación a través de la caricatura: cuando se alcanzaba un grado de referencialidad mayor, hasta de compromiso político, solía ocurrir en narraciones de corte detectivesco o policiaco. La realidad y su crítica eran más bien el objeto de las tiras o de los dibujos de prensa.

A partir de la década de los 80 del siglo $\mathrm{xx}$, se empezaron a dar cómics más referenciales y se fue desarrollando el uso de una nueva etiqueta -la de "novela gráfica"- cuando la mayoría justamente no eran novelas sino que se acercaban más al ensayo, al documental o a la autobiografía; pero la apelación "novela" pretendía legitimar el noveno arte por medio de su acercamiento a la literatura y la posibilidad de establecer un canon como lo hacen las historias literarias (Gómez Salamanca 2013: 222). En España, fueron primero obras relacionadas con el pasado de la Guerra Civil o franquista, no solo a raíz de lo que se ha denominado "memoria histórica" sino también anteriormente a este fenómeno, desde 1977, con el precursor Paracuellos de Carlos Giménez (Touton 2011). En realidad, creo que no se problematizó la naturaleza ficticia o no de las obras adscritas a esta corriente: se habló de la irrupción de nuevos "temas" (histórico, íntimo, político...), de técnicas que iban a servir un propósito más "serio" (blanco y negro, sobriedad, textos más literarios y largos...), de cómic "de autor" (Gómez Salamanca 2013: 210) y de la voluntad de granjearse un nuevo tipo de público más adulto y maduro:

La expresión "temas serios" (pese a estar ampliamente aceptada y ser frecuentemente utilizada incluso en estudios académicos) no ofrece ninguna garantía como herramienta en el estudio de la novela gráfica. Esta categoría es una puerta abierta a la indefinición y no establece ninguna diferencia entre el contenido y el tratamiento o enfoque del mismo. En algunos estudios de escasa entidad académica sobre el cómic, el de los "temas serios" es, además, un concepto que viene asociado con la madurez del medio, la de los lectores y la literaturidad entre otras cosas. (Gómez Salamanca 2013: 198)

En España, se calificó tanto de novela gráfica El arte de volar (2009) de Antonio Altarriba y Kim (biografía documentada del padre del guionista con incursiones en lo autobiográfico) como Las serpientes ciegas (2008) de Felipe Hernández Cava y Bartolomé Seguí, ficción ubicada en Estados Unidos durante la Guerra Civil española. Lo que sí interesó a los críticos fue de qué manera el cómic, arte de lo "invisible" (McCloud 1999) y arte "secuencial" (Eisner 2007), en el que el espacio interviñetal ("la viñeta en blanco" que solo existe en la cabeza del lector) juega un papel fundamental en su participación activa, resultaba ser un médium adecuado para dar a ver cierta clase de realidad: la articulación de la pequeña y la gran historia, de los acontecimientos colectivos y de su huella en forma de trauma hereditario en la mente de la víctima y del testigo, el legado 
inconsciente de la violencia en los hijos, etc. Pero, hasta donde sé yo, para dar el ejemplo de las distintas obras de Carlos Giménez, "representante de la historieta político-social" española (Guiral 1996: xx), no se han dado discusiones ni sobre el realismo de sus historias -sí sobre su limitado realismo gráfico (Guiral 1996: xx) y sobre su preciso realismo lingüístico (Vázquez Montalbán 2001)- ni sobre su grado de ficcionalidad. Sin embargo, entre la serie Paracuellos (con una fuerte dimensión autobiográfica, pero basada en recuerdos de su niñez), la serie 36-39. Malos tiempos (periodo que el autor no ha vivido, pero que ha elaborado a partir de otros testimonios y en el que inventa a unos personajes ficticios, Marcelino y su familia) o la serie Pepe, en la que el prólogo autorial explica que "todos los personajes son reales", pero donde se ve, al igual que en las obras anteriores, que por lo menos una gran parte de los diálogos son ficticios, la dimensión ficcional existe y varía. Podemos avanzar una hipótesis: quizá, por su propia cultura, anclada en el imaginario infantil, el cómic haya podido permanecer al margen de ciertas clasificaciones que, si creemos a Jorge Larrosa, servirían para controlar el papel de las narraciones en nuestras vidas:

Todo ese aparato de distinciones y jerarquía entre lo objetivo y lo subjetivo, lo real y lo imaginario, la esencia y la apariencia, etcétera, no es más que un mecanismo para controlar la capacidad productiva y creadora del lenguaje. Sostener esas fronteras y mantener a la lectura encerrada en el ámbito trivializado de lo imaginario es un modo de limitar y controlar nuestra capacidad de formación y transformación. Tomarse en serio la lectura como formación puede ser me parece un modo de quebrar esas fronteras y un modo de afirmar la potencia formativa y transformadora (productiva) de la imaginación. (Larrosa 2003: 28)

En el caso de las novelas gráficas citadas, me parece que además escapan de las sospechas de manipulación ideológica que pueden pesar en algunas novelas contemporáneas "híbridas" (entre ficción y no ficción) que recurren a un pacto de lectura ambiguo -véanse los debates en torno al alcance ideológico y ético de Los soldados de Salamina, de Javier Cercas, o de Enterrar a los muertos, de Ignacio Martínez de Pisón-, porque suelen estar precedidas por prólogos que hacen el pacto transparente (al enunciar en qué medida la dimensión histórica del relato está documentada) y sobre todo porque anuncian "desde dónde hablan", como lo ejemplifica el prólogo a 36-39. Malos tiempos de Carlos Giménez firmado por Antonio Martín:

Giménez toma partido desde la primera página de este libro. Y aunque mantiene su condena sobre todos los muertos ello no quiere decir que sea neutral [...]. Como autor, intenta conservar la imparcialidad del testigo que señala y da testimonio de las barbaridades que se ejecutaron en ambas Españas en guerra. Y sin embargo, su conciencia de hombre de bien no puede quedar enterrada bajo ese silencio que reclaman los conformistas que piden que no se remueva el pasado. Y así, pese a su deseo de ser imparcial, a Giménez le es imposible callar la verdad última. (Martín 2007: 4) 
1.2. FICCIÓN, NO FICCIÓN, ANIMACIÓN E IMÁGENES DIGITALES: NUEVOS PLANTEAMIENTOS CINEMATOGRÁFICOS

La cuestión del realismo atraviesa la crítica cinematográfica desde la aparición del cine sonoro, como prueba el ingente número de obras dedicadas a este tema; durante mucho tiempo, como en la narrativa, fue una problemática exclusiva de la ficción. Se entendía como la voluntad de hacer olvidar los artificios de la representación: "Fuertemente sustentado en el sistema de la verosimilitud, organizado de suerte que cada elemento de la ficción parezca contestar a una necesidad orgánica y parezca obligatorio con respecto a una supuesta realidad, el universo diegético cobra consistencia en un mundo posible cuya construcción, cuyo artificio y cuya arbitrariedad se borran en beneficio de una aparente naturalidad" (Aumont 1983: 107).

El movimiento realista que mayor impronta dejó en la historia del cine occidental es sin duda, en este sentido, el neorrealismo italiano, que nació a raíz de la Segunda Guerra Mundial y se extinguió a mediados de los años 50: estas películas, a menudo rodadas con poco presupuesto, que se fundamentaban en una voluntad de dar testimonio, de dejar hablar a los "sin voz", en un rechazo de la retórica (Ottavi 2007: 47) y correspondían a cierto optimismo histórico de tipo marxista (Ottavi 2007: 46), buscaban alcanzar cierta verdad, "un discurso verdadero" (Cassac 2007: 13) y lindaban a veces con el documental (Seknadje-Askénazi 2007), en particular porque los directores recurrían a menudo a decorados naturales y a actores no profesionales que representaban su propio papel.

Desde hace unos veinte años se ha vuelto a utilizar el concepto de "realismo" para referirse al grado de realidad inherente a cada obra cinematográfica. Primero porque, como ya había demostrado André Bazin, el cine filmado es huella del referente con el que estuvo en contacto y consecuentemente índice de que algo estuvo (aunque fuera una puesta en escena). Segundo, porque la experiencia visual de los colores, de las formas y de los movimientos en una pantalla en dos dimensiones guarda mucha similitud con la percepción de la realidad, como la del sonido reproducido técnicamente con la del sonido percibido en vivo. Es, el cine sonoro y en color, el médium que mejor logra la "ilusión perceptiva" -"leurre perceptif"- (Lioult 2004: 32):

Es cierto que algunos componentes de la imagen cinematográfica la predisponen a referirse a lo real, primer paso hacia esta sustitución ilusoria que consiste en hacerse pasar por la realidad y ocultar a la vez su propio estatuto de representación. Aunque esta imagen solo es un simulacro, una realidad de pantalla, muchas de sus cualidades le permiten aproximarse a lo que es una experiencia perceptiva "real" de los individuos convertidos en espectadores. (Boillat 2001: 35)

Sin embargo, se llegó a decir también que toda obra cinematográfica era ficticia por su relación espectral con un referente recortado (el espectador tiene que imaginar el fuera de campo) cuyas imágenes dicen también la ausencia. Por eso, la cuestión del "realismo" en el cine es cada vez más la de su grado de 
ficcionalidad: "Ficción y no ficción implican ambas la elaboración de un universo diegético. Se distinguen sin embargo por la naturaleza de este en una película ficticia, la diégesis es la creación de un mundo, mientras que en el polo opuesto se quiere la reproducción del mundo real" (Boillat 2001: 124). Otra manera de decirlo es la de François Niney (2009: 34): hay homogeneidad o continuidad entre la temporalidad del documental y el tiempo histórico en el que se sitúa el espectador, y heterogeneidad en el caso de la ficción.

Jean-Luc Lioult (2004: 37 y 41) propone dos tipos de relación con la realidad. Un primer tipo que tendría que ver con una "realidad de primer orden": ¿en qué medida lo que se ve es fiel a lo que se puede ver en lo afílmico, es decir lo que existe en el mundo usual, lo que la cámara graba sin preparación previa? Este primer tipo de relación interroga el grado de preparación, de modificación de la realidad, de puesta en escena antes de filmar. Y otra de segundo orden, que tendría que ver con el sentido que se da a la realidad (para dar cuenta de una realidad o de una "verdad" ${ }^{6}$ se pueden utilizar metáforas, decorados, invenciones, etc.). La congruencia entre los dos órdenes, y eso podría valer tanto para las obras de ficción como de no ficción, implicaría un mayor grado de realismo. Hay un tercer momento de intervención en las imágenes ya grabadas: el montaje y la postproducción de las imágenes, cada vez mayor con el desarrollo de las nuevas tecnologías de síntesis o digitales, un tipo de transformación que "poetiza" la obra (Boillat 2001: 242).

Del mismo modo que las teorías de Kate Hamburger o Dorit Cohn para identificar técnicas propias de la ficción o de la no ficción literarias (discurso histórico, en particular) alcanzan difícilmente valor universal y se ven puestas en tela de juicio por todo tipo de narraciones híbridas, pero sí reflejan ciertas tendencias, la mayor parte de las técnicas son compartidas en los cines de ficción y no ficción. Lo que sí se puede notar es una diferencia de gradación debido al uso de ciertos recursos narrativos o técnicos que implican más bien un "efecto documentalizante" o, por el contrario, un "efecto ficcionalizante" (enunciación, metanarratividad, voz en off, expresión de la interioridad de los personajes...). No obstante, la diferencia esencial se sitúa a nivel pragmático: la intención no es la misma, el dispositivo tiende a establecer un pacto de lectura diferente que entiende y acepta generalmente el receptor (Lioult habla para el documental de "aserción seria consentida") (2009: 33). En realidad, la realización suele diferir también bastante. En el origen histórico del documental está el rechazo al guion previo y a los actores profesionales así como la conciencia, y se supone que su declaración transparente para el espectador, de que "el documentalista graba la realidad de las modificaciones que aporta a la realidad" (Lioult 2009: 44). En la película de ficción, el guion lo suele prever casi todo. En el documental, la captación puede establecer un dispositivo que intente crear las condiciones para que "acontezca" algo, no previsto ni controlado de antemano por el director.

\footnotetext{
6 "El binomio verdad/falsedad no es por ende pertinente para distinguir la ficción del documental, mientras que la 'realidad' es propia de éste... La 'verdad' me parece un concepto más amplio que implica un vínculo entre la significación y la representación mucho más tenue que el que supone la noción de 'realidad'" (Boillat 2001: 57).
} 
En este caso el trabajo de montaje (del director y del montador o editor) es aún más fundamental. Desde luego, guion y puesta en escena son también recursos posibles del documental, como la improvisación lo es de la ficción, y no implican necesariamente más o menos "realismo de segundo orden".

Ahora bien, todos estos análisis y estas distinciones no valen cuando se trata de animación, cuya variante documental está en pleno auge ${ }^{7}$ aunque solo empieza a darse en cortometrajes en España, a menudo vinculados con cómics como es el caso de Españistán, de la burbuja inmobiliaria a la crisis de Aleix Saló (2011), o El viaje de María (2010) y Academia de especialistas (2012) del propio Miguel Gallardo. Pierde también vigencia con las nuevas tecnologías digitales: "un escritor que inventa un mundo parte de una página en blanco, la producción cinematográfica excluye tal dominio ejercido por el productor del discurso en la representación, excepto para las películas de animación o de síntesis en las que todo fue recreado" (Boillat 2001: 131). La realidad, y el movimiento no se reproducen en una co-presencia filmador-filmado, sino que el animador tiene que extraerse de esta para analizar el movimiento y recrearlo (Robach 2010: 13). De ahí que el cine de animación (tradicional o sintetizado por ordenador) se preste mejor a la expresión de realidades difícilmente filmables (interior del cuerpo humano, captación de lo infinitamente grande o pequeño, cuerpos desaparecidos y que no han sido ni fotografiados ni filmados, traumas, sueños, percepciones particulares): "El cine de animación es pues particularmente propicio para la expresión de la subjetividad. La artificialidad del dispositivo (reconstitución imagen por imagen) favorece, en efecto, por el desajuste evidente que marca con lo real, los juegos de la metáfora gráfica y así el establecimiento de un pensamiento animado (Robach 2010: 1).

En cuanto a la imagen digital, en un primer momento de su historia ha servido ante todo una estética hiperrealista ${ }^{8}$ para crear mundos imaginarios o futuristas (en España podemos citar Eva de Kike Maillo, 2012) o reconstrucciones históricas (Agora de Alejandro Amenábar, 2009), pero su uso evolucionó en Hollywood (en particular desde Sin City de Robert Rodríguez, 2005) hacia una estética irrealista que se quiere mimética de la estética de la novela gráfica (Gómez Martínez 2008: 8). En España, su uso ha podido servir también a una estética feísta, caricaturesca, por ejemplo en las películas de Torrente de Santiago Segura, o con tintes más goyescos en Las brujas de Zugarramurdi de Álex de la Iglesia, en 2013. Por otra parte, la capacidad de intervención de las herramientas digitales

\footnotetext{
${ }^{7}$ Aunque uno de los primeros documentales animados sería el de Winsor McKay, El hundimiento del Lusitania (1918), el género ha empezado a despertar el interés de productores y espectadores desde Persépolis (2007) de Marjane Satrapi y Vincent Paronnaud (adaptación del cómic de Marjane Satrapi) y de Vals con Bashir (2008) de Ari Folman (que dio lugar a una versión en novela gráfica posterior). La Muestra Internacional del Cine de Animación de Cataluña (Animac) dedicó su edición de 2013 a la animación de no ficción con el título "A través de la realidad".

8 Lo explica Andrew Darley en Cultura visual digital por los orígenes de las imágenes creadas por ordenadores: "El interés por la producción de imágenes figurativas por ordenador llegó a convertirse, a medida que ese potencial se fue materializando, en una fijación por la perfección del fotorrealismo simulado. Esta preocupación tiene una relevancia considerable para explicar el desarrollo de las formas que centran este estudio" (Darley 2002: 34).
} 
sobre cualquier tipo de imagen filmada le está quitando también a esta su estatuto de indicio de la realidad: "La tecnoimagen, la imagen tecnográfica ha dejado de ser veridiccional en la era digital" (Gubern en Valencia 2014).

Como vimos, la cuestión del documental se ha convertido en central en las teorías sobre la ficción y cuando se habla de "nuevo pacto realista" se incluye el desarrollo de documentales o formas híbridas, mixtas, comprometidas con la realidad. Cuando en España Ángel Quintana critica lo que llama el "realismo tímido"9 y defiende un cine fronterizo, se refiere tanto a obras de ficción como de no ficción, o a caballo entre las dos formas, a "filmes-ensayos" (Benavente 2012: 618-619). Este fenómeno teórico es correlativo de un aumento significativo de producciones de no ficción, que recogen reconocimientos institucionales y públicos. Este auge se debe también en estos últimos años de "crisis", en España, a que una realidad no exclusivamente subjetiva (violencia de las relaciones sociales, de la economía de libre mercado, centralidad del cuerpo desahuciado, expulsado, hambriento, desamparado por la sanidad pública y, como respuesta, protestas ciudadanas "indignadas"10...) se hace menos eludible, por lo que los creadores sienten la necesidad de darle sentido, buscándolo también, retroactivamente, en los años de una transición presentada hasta recientemente como modélica. Muchas de estas producciones, algunas inspiradas en el trabajo del director Joaquim Jordà, otras que emergen de colectivos anónimos (como Cine sin Autor, Laboratorio de Trabajadoras, Los Hijos), han optado por "una deconstrucción de las formas autoritarias del documental clásico, abriéndolo a la participación, a la improvisación y al experimento" (Moreno-Caballud 2012: 548). Además, se recurre frecuentemente a los cortometrajes de animación, algunos adaptados de cómics como lo son los de Aleix Saló cuando se trata de explicar pedagógicamente el funcionamiento del sistema financiero (bolsa, burbuja inmobiliaria, deuda de Estados y bancos, sistema hipotecario, etc. ${ }^{11}$ ).

Para explorar mejor la articulación actual entre realismo, ficción, documental y cómic me ha parecido oportuno estudiar la película María y yo de Félix Fernández de Castro, inspirada en la novela gráfica autobiográfica de Miguel Gallardo, documental-adaptación que mezcla técnicas tradicionales, animación e imágenes digitales para hablarnos de unos cuerpos dependientes, de unas mentes inadaptadas a la temporalidad de consumo de las sociedades moldeadas por el capitalismo tardío.

\footnotetext{
9 "La mayoría de las películas del realismo tímido se caracterizan por su deseo de constituirse como mundos autónomos donde las leyes del guion adquieren más importancia que el mundo que quiere reflejar. Son películas que copian o imitan el mundo, poniendo en evidencia sus múltiples limitaciones, pero en ningún caso pretenden reproducir el mundo para poder reflejar mejor sus ambigüedades" (Quintana 2005: 18).

10 Solo sobre el $15 \mathrm{M}$, el enlace siguiente recoge veintidós títulos de documentales: <http:// wiki.15m.cc/wiki/Lista_de_documentales_sobre_el_15M>.

11 Simiocracia (2012) y Europesadilla (2013) de Aleix Saló (trailers promocionales de los cómics), Historia de España for dummies (2012), de Los Monigotes, etc.
} 
2. María y yo: el Cómic y la película

\section{1. ¿Tebeos Realistas, Sensibles, Sociales?}

Miguel Gallardo, inventor de la línea chunga y, con Juan Mediavilla, del personaje de Makoki, esquizofrénico y adicto a los choques eléctricos, uno de los (anti)-héroes de la cultura underground de los 80, publica en 2007 la novela gráfica María y yo. Allí cuenta la relación del autor con su hija María, que sufre TEA (Trastornos del Espectro Autista), con un grafismo bastante naif, una imagen a veces meramente ilustrativa y unos textos explicativos y distanciados (Fig. 1) ${ }^{12}$.

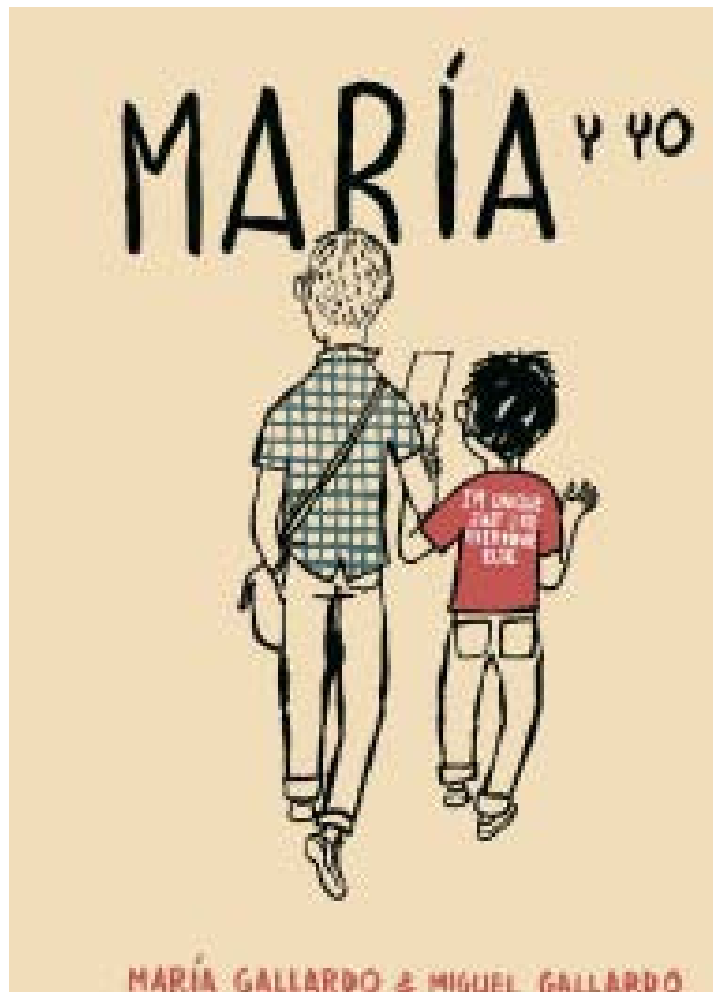

Fig. 1. Portada de María y yo

La editorial Astiberri y los animadores culturales asociaron esta obra con Arrugas (2007) de Paco Roca, una obra ficticia con un grafismo cercano a la línea clara, pero que fue precedida por un trabajo de investigación y visitas a residencias de ancianos ${ }^{13}$, y con la que será interesante cotejarla (Fig. 2).

\footnotetext{
12 Analizo más detalladamente la novela gráfica en Touton (en prensa).

${ }^{13}$ Lo cuenta Paco Roca en Emotional World Tour, obra de Miguel Gallardo y Paco Roca, que resulta
} 

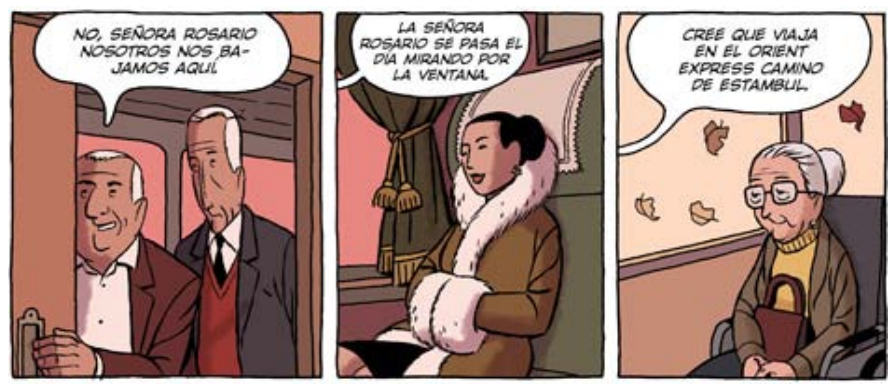

Fig. 2. Arrugas, p. 19

Los dos cómics encierran un propósito didáctico: recordar que las personas invisibilizadas por los medios de comunicación y la publicidad por ser consideradas como "antiestéticas" existen, que no tienen que ser personajes secundarios de nuestra sociedad, que nos incumbe colectiva e individualmente hacerles la vida mejor (Fig. 3).

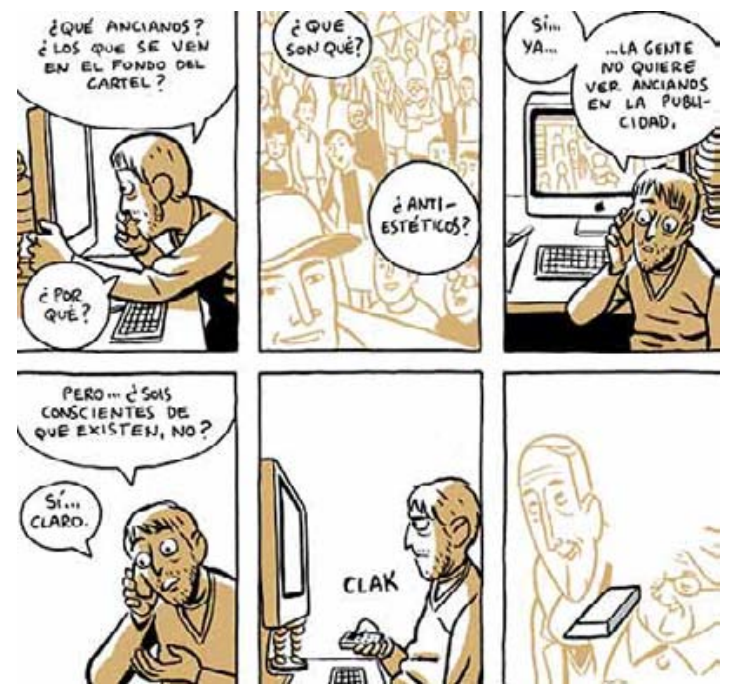

Fig. 3. Emotional World Tour (Paco Roca), p. 23

Ambicionan también, desde un punto de vista más técnico, transmitir conocimientos sobre los síntomas y el funcionamiento de esos síndromes mentales (autismo y Alzheimer). Sin embargo las dos obras (una evocación impregnada de una dimensión autobiográfica y una ficción documentada y basada en testimonios) han sido emparentadas sistemáticamente por instituciones, editores y

ser una metanarración de las dos obras anteriores y un relato de su recepción (Gallardo y Roca 2009: 28). 
críticos por sus temáticas comunes (la discapacidad y los cuidados, el funcionamiento de la memoria en un régimen extraordinario, la fantasía y el amor como principios estructurantes, etc.) bajo las denominaciones de cómic "anclado en la realidad", "de tebeo social", de "realismo social" o de "cómic sensible" (Fig. 4). El último calificativo sugirió a los dos autores el título autoirónico de la obra que iban a escribir a cuatro manos, a raíz de una gira promocional que les tocó hacer juntos: Emotional World Tour. Diarios itinerantes (2009).

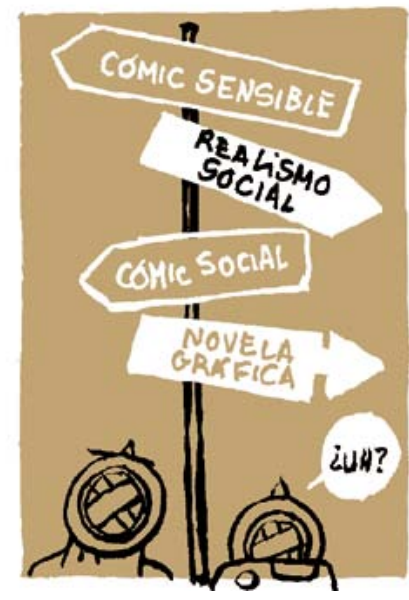

Fig. 4. Emotional World Tour (M. Gallardo), p. 56

En común, tienen pues, como objetivo, desvelar cierta verdad: se oponen al cuento de la autonomía física y emocional del hombre blanco occidental, el que está en el centro del sistema neoliberal basado en la eficacia, la gestión óptima del tiempo, la flexibilidad y la rentabilidad. Hacen visible el care, el cuidado al otro como economía subterránea sin el que nuestras sociedades no podrían funcionar, y que las ficciones populares y publicitarias contribuyen a borrar, "sociedades fascinadas por la ficción de un individuo autónomo, liberado lo más posible de sus vínculos afectivos y habitado por las necesidades del éxito social en una economía de mercado" (Brugère 2008: 17). Lo que importa es que emergen de una capacidad de escucha por parte de sus autores y exigen del lector la misma disponibilidad y curiosidad. Por otra parte, son narraciones que sí han tenido efectos directos, medibles en la realidad: los allegados de personas afectadas por una de esas disfuncionalidades regalaron los tebeos a su alrededor para "dar a entender" mejor (de manera más amable y más clara) lo que atraviesan enfermos y familiares (Gallardo y Roca 2009: 49); en torno a María, a la página de Facebook de Miguel Gallardo, a sus charlas frente a "padres y madres" se ha creado una red de solidaridad de parientes de niños autistas; y las obras han dado pie a material didáctico utilizado institucionalmente. Arrugas se ha convertido en manual para un hospital y Miguel Gallardo ha realizado cortometrajes de anima- 
ción subvencionados por la Fundación Orange (dedicada a mejorar la vida de las personas autistas) que explicitan con humor el funcionamiento del autismo: El viaje de María (2010) y Academia de especialistas (2012).

Aun así, se pueden cuestionar las diferentes etiquetas que se aplicaron a las dos historietas. Si podemos comprobar que "realismo" aquí no se utiliza solo para la ficción, son también interesantes los calificativos de "social" y "sensible". En este caso, "social" ya no remite a obras que reflejarían la lucha de clases, lo que suelen ser las novelas Ilamadas sociales. En el caso de Arrugas, predomina la universalización de la condición de decrepitud y pérdida de las facultades inherentes a la edad avanzada y los cuestionamientos metafísicos sobre las consideraciones sociales - ¿qué lugar otorga la sociedad a sus ancianos, cómo se los trata en los geriátricos, etc.?- que permanecen en un segundo plano. En María y yo, la historia particular de esta niña nacida en una familia relativamente acomodada y culta hace que en parte se dejen a un lado los problemas de clases sociales y asistencia colectiva, y se centre el propósito en la preocupación antropológica por la mirada al otro, la diferencia y el cuidado. ¿Qué decir de "tebeo sensible"? Significa seguramente que sus autores dan prueba de cierta sensibilidad, que se interesan por sentimientos y emociones, que los protagonistas no son todopoderosos, que las obras suscitan empatía. Pero lo hacen de manera muy diferente: el relato de Arrugas es más patético a pesar de sus momentos humorísticos, cuando el de María y yo, vinculado a la infancia, resulta a la vez vital y distanciado. El largometraje Arrugas, animación en 2D dirigida por Ignacio Ferreras, refuerza el recurso al pathos y a técnicas que contribuyen a desrealizar la historia (tratamiento de los colores, referencias implícitas a películas de terror, interpretación políticamente correcta de ciertos diálogos, banda sonora). Por otra parte, el uso del dibujo hace que el elemento tratado con menos realismo sea, como en el cómic, el decaimiento de los cuerpos. La impresión global es la de una película que se desvincula de lo material y de lo corporal para tender hacia lo simbólico, lo universal y lo metafísico.

\subsection{María y yo de Félix Fernández de Castro: el documental}

En comparación, la adaptación de María y yo por Félix Fernández de Castro, con Miguel y María Gallardo, presenta para nuestro estudio mucho más interés. En la película se recurre a técnicas tradicionales del documental (grabaciones de momentos de la vida diaria de María sin guion previo; entrevistas a Miguel Gallardo y a May, la madre de María, con una mirada frontal pero ligeramente ladeada con respecto a la cámara), y a animaciones, superposiciones digitales sobre imágenes grabadas, con la inclusión de muchos elementos gráficos filmados (fotografías y películas de familia, dibujos hojeados o dibujos en proceso de elaboración, etc.).

La imagen grabada revela al espectador algo que los dibujos amables y el trazado icónico de Miguel Gallardo, que tienden a infantilizar a su hija, ocultan: la visibilidad de la diferencia en el imponente cuerpo de María (tiene quince años en el momento de la grabación), su presencia intensa, y la estridencia de 
sus gritos que las onomatopeyas del cómic no traducen con la misma intensidad. Cuenta Fernández de Castro que Miguel Gallardo temía la impresión que la presencia de su hija pudiera causar en el espectador: en efecto, como comprobó Alba Rico con el cuerpo de los inmigrantes que saltan las vallas o viajan en pateras, "parte de nuestra insensibilidad [...] viene de su corporeidad excesiva" (2007: 161). El cuerpo de María publica su diferencia pero veremos cómo el director supo componer con esta "exterioridad fundamental que le impone la imagen"14 y técnicas que le permitieron imaginar la interioridad de María -sustitutivas de lo que la chica difícilmente puede expresar con palabras- para que su presencia se volviera familiar, amistosa, cómplice, y hasta artística como en el momento mágico del baile acuático de Miguel y María en la piscina. En esta secuencia de pura poesía -sublimada por la ausencia de efectos sonoros a excepción de la canción Batiscafo Katiuskas (2006) de Joan Miquel Oliver Ripoll interpretada por Antonia Font- el cuerpo de María se hace ligero como el de la niña de dos años cuyo comportamiento tiene a veces (44'33" a 46'44').

Consta la película de tres partes que el montaje hace alternar. Una primera parte retoma la "trama" del cómic María y yo (lugares, anécdotas) -el relato del viaje en avión de Miguel y María entre Barcelona y Canarias, su estancia en un "hotel resort", y las ilustraciones didáctico-humorísticas de los síntomas de sus trastornos- y retoma la evocación en Emotional World Tour de la infancia de María -los primeros indicios de "anormalidad", el difícil establecimiento de un diagnóstico a los ocho años-. Una segunda parte consta de entrevistas a Miguel Gallardo y a May, la madre de María, que continúan con una voz en off superpuesta a las imágenes del pasado (cuadernos de dibujos de Miguel, fotos y películas de familia). Una tercera parte se compone de grabaciones de María en su entorno familiar: en la casa canaria, en la escuela, en una fiesta en Barcelona, y acaba con la filmación de una llamada entre Miguel, de vuelta a Barcelona, y María, que se duerme mientras su padre le está hablando (esta lógica de cláusula final es ya más propia de la ficción que del documental).

La fidelidad a un guion escrito y dibujado por Miguel Gallardo unos años antes era una constricción importante para las secuencias adaptadas de los cómics, creando esta referencia un filtro entre la película y la realidad que se traduce de varias maneras. En el título de María y yo, este "yo", que refería al autor en la novela gráfica (en la que proclamaba el pacto autobiográfico), refiere ya no al director del documental, sino a su protagonista. La elección del título se entiende por la función intertextual con el cómic, pero el uso del pronombre de primera persona refleja también la ambigüedad de la enunciación, puesto que la huella omnipresente de Miguel Gallardo en la película (imagen, dibujos, textos que escribió para los tebeos) hace que el espectador se olvide de que no es el director ni el guionista de la película. Contribuye en particular a ello lo voz en off de Miguel que enuncia los textos narrativos o analíticos del cómic. En cuanto a situación de enunciación, el dispositivo es ficticio (la película no es una auto-

\footnotetext{
14 “Contrairement au texte scriptural, le film est confronté d'office à l'extériorité fondamentale que lui impose l'image" (Boillat 2001: 80).
} 
biografía), aunque no lo es si nos referimos a la autenticidad de las vivencias que refleja. Miguel Gallardo representa entonces su propio papel de autor a la vez que de padre, en una puesta en escena que es también mise en abyme (véanse por ejemplo, en la secuencia de la piscina, las gotas de agua en la cámara que recuerdan, al simular las que están en las gafas de Miguel, que el dibujante está dentro y fuera, el que ve y el que es visto). Miguel Gallardo cuenta en su posterior libro digital Los viajes de María la extraña impresión que le causó el haber desempeñado su propio papel dirigido por otro: impresión de ser el actor de su propia vida en unos decorados impostados (The Truman Show), impresión de vivir bajo vigilancia (1984) (Fig. 5).

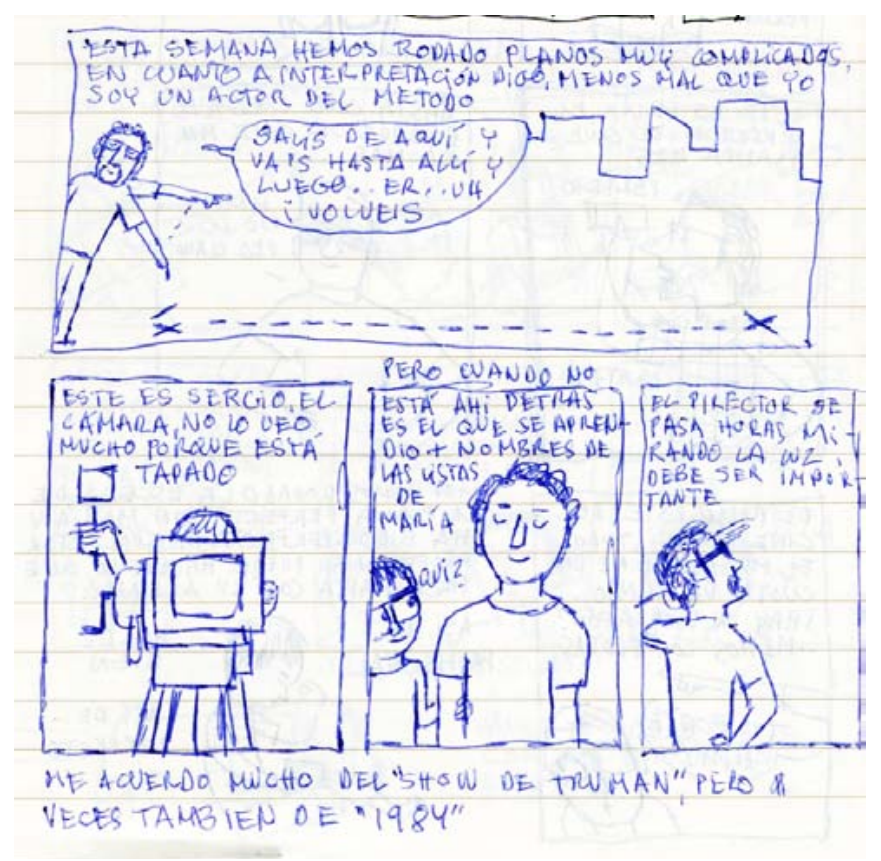

Fig. 5. Los viajes de María, p. 25

Como hemos podido observar, los protagonistas del documental son personas-personajes proteiformes. Se desdoblan por medio de sus personajes de animación, más parecidos a los personajes de los cómics pasados y de los que se iban a publicar después (volverán a ser personajes dibujados en Los viajes de María) que a su referente filmado. Las animaciones de estética resueltamente idealista de La Pera Animación, acompañadas por una banda sonora exclusivamente musical, sirven esencialmente para cuatro cosas: explicar el funcionamiento perceptivo de las personas con TEA desde un punto de vista científico y sensitivo, contar lo que ocurrió una vez en la vida de María y no se quiere obligarla a repetir, restituir su mundo onírico y el embellecimiento bajo su mirada de realidades triviales -el dibujo puede reconstruir "una imagen producida no 
por una mirada encarnada, sino por una mirada mental" (Stefanelli 2010: 288)-, expresar con distancia el pesar del padre frente al rechazo que pueda sufrir María. Este recurso nos aleja aquí del pacto de lectura "documentalizante" y nos enseña por contraste que la mirada a priori más objetiva de la cámara no basta para dar cuenta de ciertas realidades subjetivas, como cuando María ve estrellas en los granos de polvo que levanta de su asiento (fig. 6). A través de estas técnicas, y tal como aparecía en el cortometraje $A$ is for Autism (1992) de Tim Webb, el autismo se ve como un continente por descubrir y la aprensión de la realidad de los autistas como mundos posibles (es decir, ficticios), y es alejándose de la realidad de primer orden como puede traducirse mejor esta realidad de segundo orden.

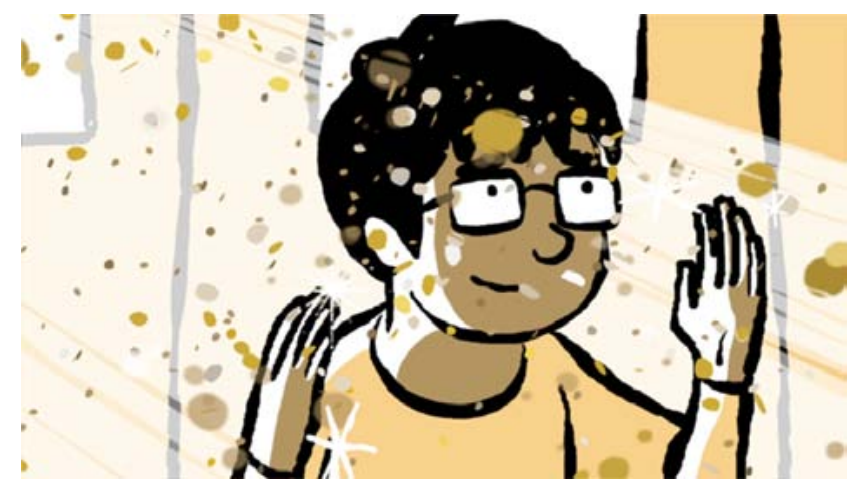

Fig. 6. María y yo (Félix Fernández de Castro, 2010, 07'54")

La relación entre padre e hija se ve también representada en una dialéctica realidad-ficción. A través de la visualización retrospectiva de los dibujos que Miguel hizo de María bebé se muestra cómo el padre consiguió obcecarse, y se negó a ver la realidad que pensaba representar: "May fue la primera que se dio cuenta de que algo no andaba bien" (9'30"). Y más adelante: "Yo la verdad, no me había enterado de nada" (10'25'). Al contrario de la madre, que advirtió un problema, él no supo leer los indicios (sueño prolongado, estereotipias, ausencia de comunicación con los padres...) que sí había dibujado, porque no cuadraban con la ficción que contaba y dibujaba en sus libretas del nacimiento de la princesita perfecta. Fue en el momento en el que llegó a ver en María al personaje del loco Makoki que había inventado veinte años antes (en la película, los electrodos que salen del casco de Makoki se prolongan artificialmente para conectarse con el supuesto gráfico del encefalograma que diagnosticó el retraso mental de la niña), cuando se creó un choque entre ficción y realidad que desestabilizó al autor y le impidió seguir dibujando a su hija durante algún tiempo (ya no podía copiar la realidad). Para el espectador, es quizá esta intertextualidad con la ficción (el relato se ve contaminado por la referencia a un mundo que tiene un grado de ficcionalidad superior) la que mejor puede hacerle tomar la medida de lo que significó para los padres traducir en realidad (práctica, afectiva) gráficos abstractos y diagnósticos herméticos. 
Cuando Miguel retoma los lápices, es para ponerlos al servicio de su niña, con un dibujo estilizado que será el de sus obras del siglo xxı. Como muestra la exhibición de la materialidad de los soportes sobre los que Miguel dibuja, esta historia es también, en efecto, la de la formación de un artista que aprende de su hija:

\begin{abstract}
Yo siempre he sido un dibujante muy meticuloso, muy amante de las referencias, de hacer pastiches de estilo, de trabajar mucho la técnica. Y de pronto, al empezar a dibujar con María, empiezo a dibujar del natural o de imaginación. [...] Y entonces me acostumbré a este tipo de dibujos rápidos, estábamos en cualquier sitio con una libreta y yo dibujaba para María y no podía estar con tonterías, de hacer esto o lo otro sino que mis dibujos se fueron convirtiendo en algo muy icónico, muy simbolista. Y cada vez se fueron simplificando más. (Fernández de Castro 2010: 25'44"'-26'25")
\end{abstract}

Con sus dibujos, Miguel ayuda a María a permanecer anclada en la realidad y a soportarla cuando le entra ansiedad, al ilustrar las listas de las personas que establece ella -con un don hipermnésico para la gente que ha llegado a cruzar su vida, y sus nombres-, y lo hace, cuando no conoce a la persona evocada, a través de la imaginación (cuenta que una vez representó una persona que en realidad era un perro). A su vez, la utilización de imágenes digitales (dibujos en sobreimpresión sobre la película: flechas, sensogramas, onomatopeyas, casilleros) para explicar las obsesiones (ordenar y repetir) o fobias (miedo al ruido, a caminar de puntillas, etc.) de María, para resaltar sus "superpoderes" ("superconcentración" para comer, hipermnesia, etc.) o imaginar su peculiar visión del mundo (cadenas de ADN de los mundos que ve en los granos de arena, continentes con nombres de personas y árboles genealógicos) es didáctica. Asimismo, esta parodia tebeística de la realidad busca traducir el humor lúdico del que quiere hacer de las vacaciones de su hija un terreno de juego y busca una complicidad no lastimosa gracias a cierta intertextualidad popular (fig. 7).

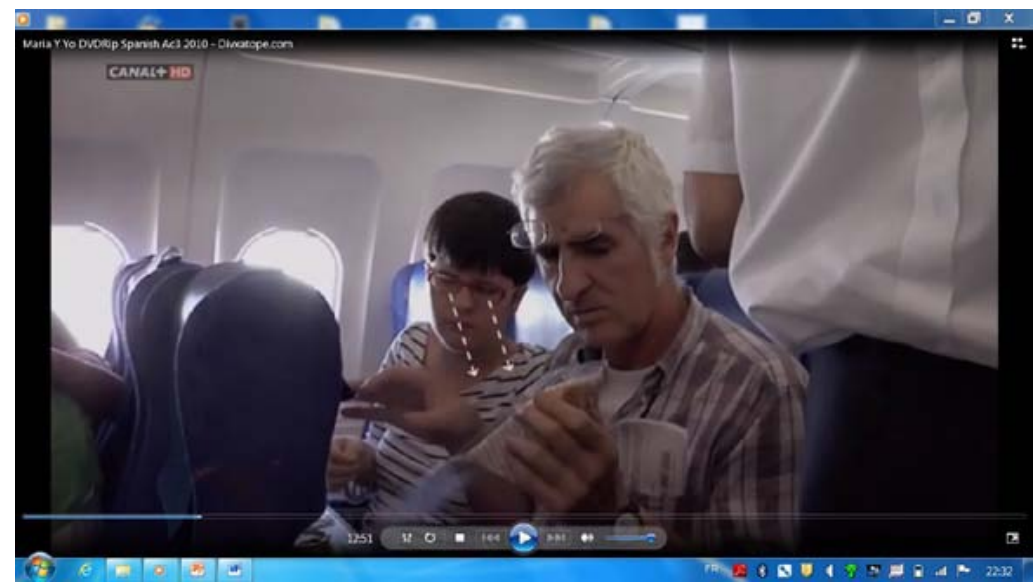

Fig. 7. María y yo (Félix Fernández de Castro, 2010, 12'52") 
Otro elemento de ficcionalización radica en la disimulación de la presencia de la cámara. En una escena fundamental, centrada en la convergencia de las miradas hacia María en el restaurante del hotel, bien podemos pensar que el dispositivo es tramposo (o que juega con el espectador más avisado), puesto que las miradas que deben ilustrar el texto dicho por Miguel, reproducido a continuación, fueron seguramente atraídas por lo menos tanto por el equipo que graba y toma el sonido como por la mera presencia de María:

Ir por ahí con María, es más o menos como ir con Madonna, entras en cualquier sitio e inmediatamente se convierte en el centro de atención. Todo el mundo la mira. Hay formas de mirar curiosas, de extrañeza, con una cierta comprensión, hasta cariñosas algunas veces. Pero otras veces veo cosas que no me gustan en las caras de la gente que mira a María. Esas caras a veces me joroban. Y a veces me ponen triste. (Fernández de Castro 2010: 48'56"-49'29")

Por otra parte, este sentimiento de acoso provocado por las miradas ajenas que se suceden y se acumulan se ve reflejado por el uso de una técnica permitida por el montaje digitalizado que toma prestado del cómic la representación espacializada del tiempo: se superponen en una misma imagen planos detalles centrados en los ojos de varias personas, en encuadres pequeños de formatos y tamaños variables, que aplastan visualmente a los dos protagonistas, dibujados como sombras de sí mismos (Fig. 8).

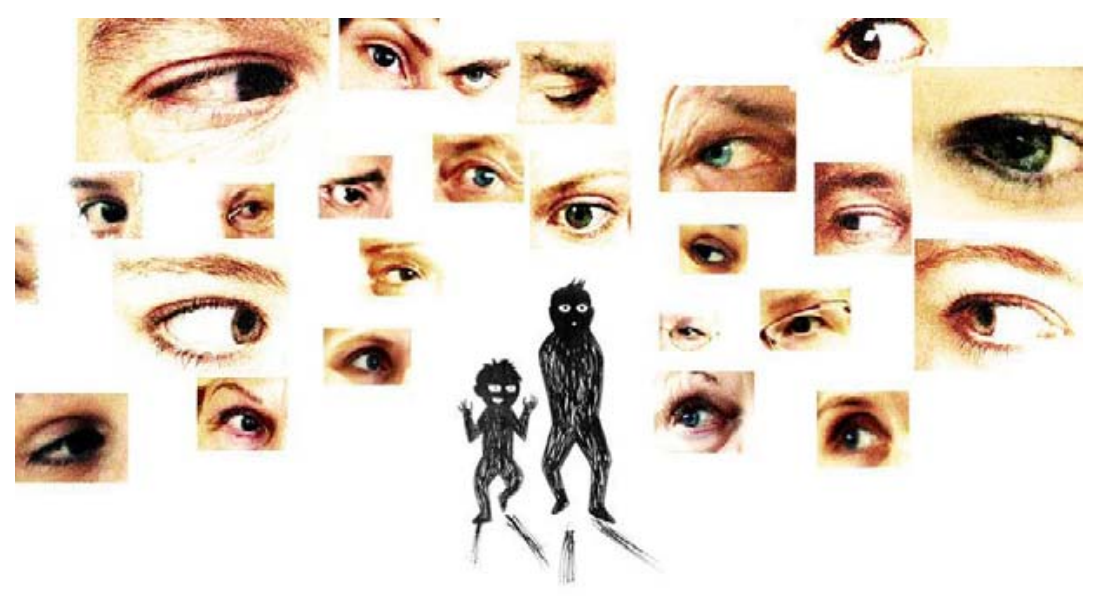

Fig. 8. María y yo (Félix Fernández de Castro, 2010, 49'24")

Finalmente, la manera de filmar a los turistas que están en el hotel resort es ficcionalizante y satírica. A la mirada comprensiva, íntima, que se les dedica a padre e hija se opone la mirada distanciada que objetualiza, fragmenta, afea esos cuerpos deformes, blandos y pasivos de los "guiris", quienes tienen los mismos rituales que María, con la diferencia de que los suyos parecen vulgares, no poéticos. En esta isla en la isla, especie de heterotopía vulgar en la que se 
refugia el padre por las comodidades materiales que le proporciona, la vida de los protagonistas de la película y la de los turistas extranjeros son estancas. La inversión de las miradas de desprecio e ignorancia (los turistas aparecen como extraterrestres sin ninguna interioridad ni voz, puros consumidores) crea una complicidad confortable con el espectador cuya aprensión empática de la realidad se agota en María y su entorno. Los veraneantes vacíos sirven de valedores a María y la inversión de las miradas plasma la solidaridad del padre (está del lado de su hija y no del lado de los que la $\operatorname{miran^{15}}$ ), que sirve quizá para que, a pesar del retrato laudatorio de un dibujante, conocido por su acidez, a esta obra no se le pueda reprochar su "buenismo". Por fin, la representación caricaturesca de los otros clientes del hotel se lee como mimética de cierta mirada condescendiente de Miguel, y explica la elección de este lugar de veraneo poco atractivo: es tanto más fácil que el padre se deje llevar por su relación fusional, corporal, edípica con su hija de la que solo disfruta durante las vacaciones, y privilegie para ella el principio de placer al de realidad, cuanto que el juicio de los que lo rodean le es indiferente (de alguna manera, los considera como puras exterioridades).

Si la autoridad de la enunciación, en varios momentos subrayados anteriormente, se desplaza en parte hacia el personaje -lo que permite al director hacernos compartir y ocupar el lugar del "otro"-, el "megaenunciador" deja en cambio su impronta en las entrevistas, que nos devuelven otra vez a la realidad del documental, en un montaje fragmentario, no cronológico, hecho de rupturas y paralelismos, y en la banda sonora. Como para contrarrestar la inmediatez del propósito didáctico, el discurso del director exige del espectador una fuerte inferencia. Radica en particular en el cotejo de las respuestas a las preguntas hechas a los dos padres (que no se oyen en la película, como tampoco se ve al entrevistador), gracias al montaje en alternancia de sus respuestas, que responden a escenas de la vida de María grabadas con uno u otro. Lo que muestra este montaje en alternancia es cómo difieren las soluciones psíquicas que encontraron ambos padres para vivir su relación llena de amor con su hija. La manera de gestionar la realidad de May sirve así de contrapunto a la de Miguel, de la cual revela ciertos aspectos. La realidad de la madre está en la vida cotidiana y un sufrimiento, un cansancio, encarados con fuerza (a pesar de la ayuda material de dos chicas que parecen turnarse al lado de María en casa); la del padre tiene lugar dentro de un paréntesis temporal, en la fusión, la adhesión al mundo de su hija y la imaginación (traducidos por técnicas de representación burlonas, paródicas o poéticas). Una está en la preocupación por el porvenir (le gustaría que alguien cuidara afectivamente de María después de su muerte), otro en la negación del tiempo que pasa (sigue teniendo con su hija adolescente los mismos gestos que los que se pueden tener con un niño de dos años y confiesa que

15 "Otra cosa que explico siempre en mis charlas a padres, como un ejercicio de autoestima y valoración, es que cuando yo voy con María estoy de su lado, nunca del de los que miran. Estoy en el equipo de María y, como bien dices, tiendo a veces a hacer de menos a los demás por su comportamiento" (Correspondencia personal con Miguel Gallardo, del 2 de mayo de 2013, a quien agradezco mucho la generosidad). 
preferiría que María muriera antes que él, para no dejarla desamparada). Pero lo que queda claro también, a pesar de que Miguel Gallardo asume totalmente y con entera dedicación el cuidado a su hija cuando están juntos -y se puede considerar como uno de "esas madres de ambos sexos" de las/los que tan bien habló Santiago Alba Rico (2007: 107)- es que la sociedad hace que el cuidado de andar por casa, cotidiano, alienante (seguramente a pesar del propio padre), es el de la madre. Se da la impresión de que estas "servidumbres civilizadoras en el cuidado de un hijo discapacitado o enfermo, necesitado de atención durante toda la vida, abocado a una infancia prolongada" (Alba Rico 2007: 183), lo son para el padre, pero no pueden serlo aún para la madre por motivos quizá vinculados con la propia historia de ambos, y también sociales y estructurales.

\section{CONCLUSIÓN}

Si hoy en día parece muy difícil establecer lo que es o no es una obra realista, podemos pensar que la relación de una obra con la realidad estriba en cuatro elementos fundamentales: la selección de los objetos para ella dignos de atención, la calidad de la mirada que se les dedica, el estatuto de lo que se concibe como real, y el grado de influencia que un artista pretende que su obra siga teniendo en cierto tipo de realidad (mental, con la intención de desvelar cierta verdad oculta, poner a distancia una realidad vivida como "natural", dar cuerpo a pensamientos utópicos, etc.; o pragmática, en particular, empujar a la acción política).

En el documental María y yo, a pesar de que podamos dudar de la espontaneidad de ciertas tomas, de que sepamos de la manipulación de la cámara, de que se recurra a cierta poetización, entendemos que estos juegos con un "efecto ficcionalizante" sirven la dimensión más utópica de la película, sirven para contar una realidad que solo en parte se puede grabar: contar cómo el amor puede permitir cambiar las relaciones sociales, contar cómo el que supuestamente sabe menos puede enseñar al otro, mostrar cómo se puede ser feliz siendo "diferente", contribuir a hacer pensar que "le sexe de la sollicitude" (Brugère 2008) y la ternura pueden cambiar (el objeto de atención). La complejidad de los puntos de vista y la intermedialidad configuran una obra dialógica, en la que se entrecruzan las miradas de Miguel (cuando María era bebé, cuando escribió la novela gráfica, cuando lo entrevistan), de María (que dice a su padre "Tú y yo", y lo convierte así también en el objeto de su mirada, mostrando que la dependencia se da en términos de reciprocidad), de May, de Fernández de Castro y la del espectador para configurar una realidad (la calidad de las miradas) mucho más compleja, hecha de capas temporales y posicionamientos distintos.

¿Se podría objetar que, con su recurso humorístico y sentimental a ciertas técnicas de la ficción, el documental María y yo establece un pacto de complicidad cómodo con el lector que lo confirma en sus buenos sentimientos y su buena conciencia? Quiero pensar que no. Primero porque lo que atenúa el dibujo lo expone violentamente la película: la presencia física y vocal de María, y una intimidad estrecha en la que Miguel Gallardo se expone, al dejarla filmar. Es 
cierto que de algún modo puede verse la película como el relato ejemplar de la educación y la formación de un hombre, padre y artista que, como preconizaba María Zambrano, tuvo que aprender a perderse para encontrarse (Larrosa 2003: 102). Pero me parece que gracias a la filmación valiente de un cuerpo vulnerable y de los que dedican su tiempo a cuidar de él, de lo que pueden las redes de solidaridad frente a la ciencia o la medicina, esta película sin propósito político explícito enlaza con ciertos pensamientos ecofeministas que creen posible una revolución desde la vinculación entre cuidados y procomún (Pérez Orozco 2012). Además, la mezcla de dialogismo y de didactismo, de moral práctica (generosidad y dedicación) y de transgresión, de personas y personajes hace que el espectador del documental no solo vea su libido sciendi despertada sino también una libido cargada de deseos, sentimientos, sensaciones, que se supone más propia de la ficción (Lioult 2004: 131) y que, gracias a ello, esta obra con un pie en la realidad y un pie en la utopía (el estatuto de la realidad) contribuye a modificar las jerarquías de subjetividades y emociones al uso. Y de esta manera, una de las influencias sobre la realidad de esta película, si me refiero a mi propia experiencia, podría ser política y psicológica. Incita a preguntarse, como lo hace cierto pensamiento feminista ${ }^{16}$, por qué se consideran los cuidados como una carga y no como una riqueza, incita al lector a detenerse en su carrera por el rendimiento, a concederse tiempo para ir al encuentro del otro y de su propia experiencia:

La experiencia, la posibilidad de que algo nos pase, o nos acontezca, o nos llegue, requiere un gesto de interrupción, un gesto que es casi imposible en los tiempos que corren: requiere pararse a pensar, pararse a mirar, pararse a escuchar, pensar más despacio, mirar más despacio y escuchar más despacio, pararse a sentir, sentir más despacio, demorarse en los detalles, suspender la opinión, suspender el juicio, suspender la voluntad, suspender el automatismo de la acción, cultivar la atención y la delicadeza, abrir los ojos y los oídos, charlar sobre lo que nos pasa, aprender la lentitud, escuchar a los demás, cultivar el arte del encuentro, callar mucho, tener paciencia, darse tiempo y espacio. (Larrosa 2003: 96)

\section{OBRAS CITADAS}

Alba Rico, Santiago (2007): Leer con niños. Barcelona, Caballo de Troya.

Aumont, Jacques (1983): "Le réalisme au cinema". En: Jacques Aumont et al. (eds.): L'esthétique du film. París, Nathan, pp. 96-108.

Baetens, Jan, (2001): "Revealing Traces: A New Theory of Graphic Enunciation". En: Robin Varnum y Christina T. Gibbons (eds.): The Language of Comics: Word and Image. Jackson, UP of Mississippi, pp. 145-155.

\footnotetext{
16 " ¿Por qué es más atractiva la idea de no cuidar que la de cuidar?; ¿cómo desafiar la fascinación de la independencia y la autonomía plena que produce este ideal?; y, sobre todo, ¿por qué habría que hacerlo?" (Gil 2011: 39).
} 
Benavente, Fran (2012): "Formas de resistencia en el documental español contemporáneo: en busca de los gestos radicales perdidos". En: Luis Moreno Caballud (ed): La imaginación sostenible: culturas y crisis económica en la España actual. Hispanic Review, vol. 80, n. ${ }^{\circ}$ 4, pp. 607-629.

Boillat, Alain (2001): La fiction au cinéma. París, L'Harmattan.

Brugère, Fabienne (2008): Le sexe de la sollicitude. París, Seuil.

Cassac, Michel (2004): "Introduction". En: Michel Cassac (ed.): Littérature et cinéma néoréalistes. Réalisme, réel et représentation. París, L'Harmattan, pp. 9-19.

Chirbes, Rafael (2007): Crematorio. Madrid, Anagrama.

Darley, Andrew (2002): Cultura visual digital. Barcelona, Paidós.

Eisner, Will (2007): El cómic y el arte secuencial [1990], trad. de Enrique S. Abulí. Barcelona, Norma.

Fernández de Castro, Félix (2010): María y yo (guion de Félix Fernández de Castro e Ibon Olaskoaga). Barcelona, Cameo, D. L.

Ferreras, Ignacio (2011): Arrugas (guion de Ignacio Ferreras, Rosana Cecchini, Ángel de la Cruz y Paco Roca). España, Perro Verde Films.

Gallardo, Miguel, y Roca, Paco (2009): Emotional World Tour. Diarios itinerantes. Bilbao, Astiberri.

Gallardo, Miguel, y Gallardo, María (2011): Los viajes de María, libro electrónico, producción Yayaki.

Gallardo, Miguel (2012): María y yo [2007]. Bilbao, Astiberri.

Gil, Sylvia L. (2011): Nuevo feminismos. Sentidos comunes en la dispersión. Madrid, Traficantes de Sueños.

Gómez Martínez, Luisa (2008): "Cómic cinematizado: el realismo de tercer orden". En: Revista Digital Universitaria. Educación y nuevas tecnologías, vol. 9, n. ${ }^{\circ} 6$, disponible en <http://www.revista.unam.mx/vol.9/num6/art38/int38.htm>. Última visita: 21.01.2013.

Gómez Salamanca, Daniel (2013): Tebeo, cómic y novela gráfica: la influencia de la novela gráfica en la industria del cómic en España. Tesis doctoral inédita. Barcelona, Universitat Ramon Llull.

Guiral, Antonio (1996): Veinte años de cómic. Selección e introducción [1993]. Barcelona, Vicens-Vives.

Groensteen, Thierry (2011): Bande dessinée et narration. Système de la bande dessinée 2. París, Presses Universitaires de France.

(2012): "Réalisme" (entrada del Dictionnaire esthétique et thématique de la bande dessinée). En: neuvième art 2.0, <http://neuviemeart.citebd.org/spip.php?article573>. Última visita: 01.12.2013.

Hamon, Philippe (1989): "L'architecture/le sens/le réel/la représentation". En: Jean Bessière (ed.): Roman, réalités, réalismes. París, Presses Universitaires de France / Université de Picardie, pp. 31-39.

Larrosa, Jorge (2003): La experiencia de la lectura. Estudios sobre literatura y formación. México, Fondo de Cultura Económica.

Lioult, Jean-Luc (2004): A l'enseigne du réel. Penser le documentaire. Aix-en-Provence, Publications de l'Université de Provence. 
Martín, Antonio (2007): "Malos tiempos. Los desastres de la guerra...". Prólogo a Carlos Giménez: 36-39. Malos Tiempos. Barcelona, Glénat, pp. 3-4.

McCloud, Scott (1999): L'art invisible [1992], trad. de Dominique Petitfaux. París, Delcourt G. Productions.

Moreno-Caballud, Luis (2012): "La imaginación sostenible: culturas y crisis económica en la España actual". En: Hispanic Review, vol. 80, n. ${ }^{\circ} 4$, pp. 535-555.

Niney, François (2009): Le documentaire et ses faux-semblants. París, Klincksieck.

Ottavi, Antoine (2007). "Néo-réalisme: le malentendu". En: Michel Cassac (ed.): Littérature et cinéma néoréalistes. Réalisme, réel et représentation. París, L'Harmattan, pp. 4556.

Pérez Orozco, Amaia (2012): "De vidas vivibles y producción imposible". En: Rebelión.org, <http://www.rebelion.org/noticia.php?id=144215>. Última visita: 07.09.2013.

Quintana, Ángel (2005): "Modelos realistas en un tiempo de emergencias de lo político". En: Archivos de la Filmoteca, n. ${ }^{\circ} 49$, pp. 11-31.

Robach Clémentine (2010): De l'animation dans le cinéma documentaire. Tesina inédita. École Supérieure d'Arts Dramatiques, París.

Roca, Paco (2007): Arrugas. Bilbao, Astiberri.

Seknadje-Askénazi, Enrique (2007): "À propos de la distinction dans le champ du cinéma, entre néoréalisme littéraire et néoréalisme documentaire". En: Michel Cassac (ed.): Littérature et cinéma néoréalistes. Réalisme, réel et représentation. París, L'Harmattan, pp. 229-243.

Stefanelli, Matteo (2010). "Du 'cinéma-centrisme' dans le champ de la bande dessinée". En: Alain Boillat (dir.): Les Cases à l'écran: bande dessinée et cinéma en dialogue. Ginebra, Georg, pp. 283-301.

Touton, Isabelle (2004): L'image du Siècle d'or dans le roman historique contemporain espagnol (1975-2000). Tesis doctoral inédita. Université de Toulouse.

(2011): "La bande dessinée de témoignage en Espagne. De l'enfermement traumatique à la construction de l'événement". En: Dominique Breton y Elvire Gomez-Vidal Bernard (dirs.): Clôtures et Mondes clos dans les espaces ibériques et ibéro-américains. Burdeos, PUB, pp. 369-392.

(en prensa): "María y yo (Miguel Gallardo, 2008 y Félix Fernández de Castro, 2010). Regard(s) sur le handicap et la relation père-fille". En: Benoît Mitaine, Isabelle Schmidt y David Roche (dirs.): Bande dessinée et adaptations. Clermont Ferrand, Presses Universitaires de Clermont Ferrand.

Valencia, Roberto (2014-en preparación): Binomios. Conversaciones sobre ideas en crisis en la creación contemporánea. Zaragoza, Institución Fernando el Católico.

Vázquez Montalbán, Manuel (2001): "Dibujar la memoria, dibujar el deseo". En: Carlos Giménez, <http://www.carlosgimenez.com/obra/rambla.htm>. Última visita: 01.11.2013.

Webb, Tim (1992): A is for Autism. Gran Bretaña, Dick Arnall. 